\title{
A Single Infusion of Brain-Derived Neurotrophic Factor into the Ventral Tegmental Area Induces Long-Lasting Potentiation of Cocaine Seeking after Withdrawal
}

\author{
Lin Lu, Jack Dempsey, Shirley Y. Liu, Jennifer M. Bossert, and Yavin Shaham \\ Behavioral Neuroscience Branch, Intramural Research Program, National Institute on Drug Abuse, National Institutes of Health, Department of Health and \\ Human Services, Baltimore, Maryland 21224
}

\begin{abstract}
Cocaine addiction in humans is associated with long-term propensity to relapse. Using a rat relapse model, we found that cocaine seeking induced by exposure to cocaine-associated cues progressively increases after withdrawal. This progressive increase is associated with increases in brain-derived nerve growth factor (BDNF) levels within the mesolimbic dopamine system. Based on these findings, we studied whether BDNF infusions into the ventral tegmental area (VTA), the cell body region of mesolimbic dopamine neurons, would potentiate cocaine seeking after withdrawal. Rats were trained to self-administer cocaine for $10 \mathrm{~d}$, and cocaine seeking was measured in extinction tests 3,10 , or $30 \mathrm{~d}$ after withdrawal. During testing, rats were exposed to contextual cues that had predicted cocaine availability during training, and lever presses resulted in contingent presentations of a discrete tone-light cue that was previously temporally paired with cocaine infusions. BDNF $(0-0.75 \mu \mathrm{g} /$ site) or nerve growth factor (NGF; $0-0.75 \mu \mathrm{g} / \mathrm{site}$ ) was infused into the VTA $1-2 \mathrm{hr}$ after the last self-administration session. To examine the role of the mitogen-activated protein kinase (MAPK) pathway in BDNF effects, U0126 (1 $\mu \mathrm{g} / \mathrm{site}$ ), an MEK inhibitor, was used. A single intra-VTA infusion of BDNF, but not NGF, induced long-lasting enhancement of cocaine seeking for up to $30 \mathrm{~d}$, an effect reversed by U0126. In contrast, neither BDNF infusions into the substantia nigra, nor acute intra-VTA BDNF infusions $2 \mathrm{hr}$ before testing on day 3 of withdrawal, were effective. These data suggest that BDNF-mediated neuroadaptations in mesolimbic areas are involved in the persistent cocaine seeking induced by exposure to drug cues after withdrawal.
\end{abstract}

Key words: brain-derived nerve growth factor; drug self-administration; extinction; growth factors; MAP kinase; reinstatement; relapse; substantia nigra

\section{Introduction}

In humans, exposure to cues associated with cocaine use can induce drug relapse after many months of abstinence (O’Brien, 1997). In rats, exposure to cocaine cues provokes drug seeking several months after withdrawal (Ciccocioppo et al., 2001). However, until recently (Tran-Nguyen et al., 1998), the impact of the cocaine withdrawal period on vulnerability to drug seeking induced by exposure to drug-associated cues has not been systematically examined. Using a rat relapse model (Shalev et al., 2002), we assessed cocaine seeking induced by exposure to drug cues, as measured in extinction and cue-induced reinstatement tests, after $1,2,4,7,15,29$, and $60 \mathrm{~d}$ of withdrawal and found that drug seeking in these tests progressively increases, or incubates, after withdrawal (Grimm et al., 2001). Subsequently, we characterized cocaine and sucrose (a nondrug reward in rats) seeking over

Received 0ct. 28, 2003; revised Dec. 18, 2003; accepted Dec. 22, 2003.

This work was supported by the National Institute on Drug Abuse, Intramural Research Program. We thank Drs. Barry Hoffer, Yun Wang, Dorit Ron, Bruce Hope, and Jane Stewart for helpful suggestions and comments. We also thank Polly Robarts and Kelly Badger for technical assistance.

Correspondence should be addressed to Dr. Yavin Shaham, Behavioral Neuroscience Branch, Intramural Research Program, National Institute on Drug Abuse, National Institutes of Health, 5500 Nathan Shock Drive, Baltimore, MD 21224. E-mail:yshaham@intra.nida.nih.gov.

DOI:10.1523/JNEUROSCI.5124-03.2004

Copyright $\odot 2004$ Society for Neuroscience $\quad$ 0270-6474/04/241604-08\$15.00/0 withdrawal periods of up to 6 months (Shaham, 2002; Grimm et al., 2003). Cocaine or sucrose seeking induced by re-exposure to the reward cues after withdrawal followed an inverted U-shaped curve, indicating that incubation of reward seeking is not drugspecific. However, for cocaine seeking, responding peaks after 1 month and persists for up to 3 months, whereas for sucrose seeking, responding peaks after $1-4$ weeks, but completely decays after 2 months.

The persistent cocaine seeking after prolonged withdrawal periods may be mediated by neuroadaptations within the mesolimbic dopamine system that are induced by chronic cocaine exposure and subsequent withdrawal (White and Kalivas, 1998; Nestler, 2001). Based on this postulation, we studied whether the persistent increase in cocaine seeking after withdrawal is associated with alterations in brain-derived nerve growth factor (BDNF) in the ventral tegmental area (VTA), accumbens, and amygdala (Grimm et al., 2003). BDNF is involved in different forms of neuronal plasticity (Thoenen, 1995) and the survival and function of dopamine neurons (Hyman et al., 1991). BDNF infusions into mesolimbic areas increase psychostimulantinduced locomotion (Pierce and Bari, 2001) and cocaineinduced enhancement of responding for cues paired with water reward (Horger et al., 1999). Also, BDNF expression in mesocor- 
ticolimbic areas is increased after amphetamine exposure (Meredith et al., 2002).

We found that BDNF levels in the VTA, accumbens, and amygdala progressively increase after withdrawal from cocaine, but not sucrose, self-administration (Grimm et al., 2003). Furthermore, we found that the time-dependent changes in BDNF levels in the VTA, the cell body region of mesolimbic dopamine neurons, most closely parallel those of drug seeking. These findings, however, are correlational and, therefore, do not establish a direct role for BDNF in cocaine seeking.

Here, we studied whether intra-VTA BDNF infusions would enhance cocaine seeking after withdrawal, as measured in extinction tests wherein rats are re-exposed to contextual cues previously paired with cocaine availability, and lever presses result in contingent presentations of a discrete cue previously paired with cocaine infusions. We hypothesized that BDNF infusions would enhance cocaine seeking during the first several days of withdrawal, when cocaine seeking is substantially lower than it is after 1-3 months (Grimm et al., 2001, 2003). We also studied the role of the mitogen-activated protein kinase (MAPK) pathway, which is involved in BDNF effects (Poo, 2001; Shirayama et al., 2002).

\section{Materials and Methods \\ Subjects}

The subjects were 199 male Long-Evans rats (Charles River, Raleigh, NC) weighing 350-400 gm before surgery. Rats were housed in the animal facility and were maintained on a reverse $12 \mathrm{hr}$ light/dark cycle (lights off at 9:00 or 10:00 A.M.) with food and water available ad libitum in the home cage. Experimental procedures followed the Principles of Laboratory Animal Care (National Institutes of Health publication number 86-23, 1996).

\section{Intracranial and intravenous surgery}

Rats were anesthetized with a xylazine-ketamine mixture $(10+100$ $\mathrm{mg} / \mathrm{kg}$, i.p.), and permanent guide cannulas (23 gauge; Plastics One, Roanoke, VA) were implanted bilaterally $1 \mathrm{~mm}$ above the VTA or substantia nigra (SN). The coordinates (Paxinos and Watson, 1998) for the VTA were: anteroposterior (AP) $-5.2 \mathrm{~mm}$; lateral $(\mathrm{L}) \pm 1.8 \mathrm{~mm}\left(10^{\circ}\right.$ angle), and dorsoventral (DV) $-7.5 \mathrm{~mm}$. Cannulas were aimed at the middle part of the VTA, where tyrosine hydroxylase staining is much higher than in the anterior or posterior portions of the VTA (Swanson, 1982). The coordinates for the SN were: $\mathrm{AP}-5.2 \mathrm{~mm} ; \mathrm{L} \pm 2.8 \mathrm{~mm}\left(10^{\circ}\right.$ angle), and DV $-7.5 \mathrm{~mm}$. After cannulas implantation, catheters were inserted into the jugular vein and were passed subcutaneously to the top of the skull. The catheters were then attached to a modified 22 gauge cannula (Plastics One) and mounted to the rat's skull with dental cement (Shalev et al., 2001). Buprenorphine $(0.1 \mathrm{mg} / \mathrm{kg}$, s.c.) was given as an analgesic after surgery, and rats were given $5-7 \mathrm{~d}$ to recover from surgery. Catheters were flushed with sterile saline containing gentamycin $(0.08$ $\mathrm{mg} / \mathrm{ml}$ ) every $24-48 \mathrm{hr}$ during the recovery and training phases.

\section{Intracranial infusions and histology}

Intracranial microinjections of BDNF or NGF (R \& D Systems, Minneapolis, MN) were made with $10 \mu$ l Hamilton syringes (Hamilton, Reno, $\mathrm{NV}$ ) that were connected via polyethylene-50 tubing to 30 gauge injectors (Plastics One). BDNF and NGF were dissolved in sterile PBS-saline solutions $(1: 1, \mathrm{v} / \mathrm{v})$ and were infused bilaterally to the VTA or $\mathrm{SN}$ at a volume of $0.5 \mu \mathrm{l} /$ side. The MEK inhibitor U0126 (Calbiochem, La Jolla, $\mathrm{CA}$ ), was dissolved in $10 \%$ DMSO and was infused bilaterally into the VTA. Infusions were performed over $15 \mathrm{~min}$, and the injectors were left in place for an additional $5 \mathrm{~min}$. At the end of the experiments, rats were anesthetized with ketamine-xylazine $(100+10 \mathrm{mg} / \mathrm{kg}$, i.p. $)$ and were infused with 2\% Evans Blue ( $0.25 \mu$ l per side; Sigma, St. Louis, MO) into the VTA or SN. Rats were then decapitated, and the brains were removed. Coronal sections $(50 \mu \mathrm{m})$ were sliced on a freezing cryostat, and the sections were stained with cresyl violet (ICN Biomedicals, Aurora, OH). Eleven rats were excluded because the tip of the injectors was outside of the VTA or SN, as anatomically defined by the atlas of Paxinos and Watson (1998).

\section{Apparatus}

The self-administration chambers, controlled by a Med Associates (Georgia, VT) system, had two levers located $9 \mathrm{~cm}$ above the grid floor, but only one lever (an active, retractable lever) activated the infusion pump. Presses on the other lever (an inactive, stationary lever) were also recorded. The modified cannula on the rat's skull was connected to a liquid swivel (Instech, Plymouth Meeting, PA) with polyethylene-50 tubing that was protected by a metal spring and connected to the syringe (20 $\mathrm{ml}$ ) of the infusion pump.

\section{Procedures}

The experiments consisted of three phases: self-administration training, withdrawal, and tests for cocaine seeking under extinction conditions. During the training phase $(10 \mathrm{~d})$, rats were trained to lever press for cocaine infusions; each infusion was paired with a discrete tone-light cue. During the withdrawal phase, rats were not exposed to cocaine or to cues associated with cocaine self-administration. During the tests for cocaine seeking, rats were exposed to the cocaine-associated contextual cues that predicted cocaine availability during training (e.g., house light, lever insertion) and responding on the previously active lever resulted in contingent presentations of a discrete tone-light cue that was previously paired with cocaine infusions. Rats in experiments $1-3$ and 5 were tested for $2 \mathrm{hr}$ for cocaine seeking under extinction conditions that were conducted 3 and $10 \mathrm{~d}$ or 3 and $30 \mathrm{~d}$ after withdrawal, respectively. Rats in experiment 4 were tested for cocaine seeking under extinction conditions for $2 \mathrm{hr}$ after $3 \mathrm{~d}$ of withdrawal. The procedure used here to assess cocaine seeking after withdrawal is different from our previous procedures (Grimm et al., 2001, 2002, 2003) in two ways.

First, in the present experiments, we tested for cocaine seeking using the same groups of rats on day 3 and 10 or day 3 and 30 withdrawal, whereas in our previous studies independent groups of rats were tested after withdrawal. In pilot studies, we found that increased cocaine seeking in the extinction and cue-induced reinstatement tests is reliably observed in rats tested twice after 1 and $15 \mathrm{~d}$. Thus, repeated testing allows us to decrease the number of subjects needed for the experiments described below.

Second, in the present experiment, we assessed cocaine seeking in an extinction test in which rats were exposed to contextual cues that had previously indicated cocaine availability during training (e.g., house light, lever insertion), and lever presses resulted in contingent presentations of a discrete tone-light cue that was previously temporally paired with each cocaine infusion during training. In previous studies, we initially determined cocaine seeking in an extinction test in the presence of the contextual cues, but in the absence of the discrete tone-light cue. Subsequently, we determined cue-induced reinstatement of cocaine seeking in a test in which responding led to presentations of the discrete tone-light cue, which serves as a conditioned reinforcer during this test. We found, however, that cocaine seeking in the extinction and the cueinduced reinstatement tests followed a similar time course and was highly correlated (Grimm et al., 2001, 2003), suggesting that the different sets of cocaine cues, which control behavior in these two tests, induce a similar motivational state that underlies drug seeking after withdrawal. Therefore, in the present experiments we assessed cocaine seeking in an extinction test in which rats were exposed to contextual cues previously associated with cocaine availability, and lever presses resulted in contingent presentations of a discrete tone-light cue that was previously temporally paired with cocaine infusions. Similar extinction procedures have been used to assess behavioral and neuronal mechanisms underlying cue-controlled operant responding previously maintained by drug (Phillips et al., 1994; Shalev et al., 2001) or non-drug reinforcers (Balleine and Dickinson, 1998). Furthermore, we recently used the extinction procedure used here (lever presses results in contingent tone-light cue presentations) and found that cocaine seeking after withdrawal followed a time course similar to that previously observed in extinction tests conducted in the absence of the discrete tone-light cue or in the subsequent cueinduced reinstatement test (Shaham, 2002). 
Training phase

On the first day of training, rats were brought to the self-administration room where they were chronically housed in the experimental chambers. Rats were trained to self-administer cocaine- $\mathrm{HCl}$ (supplied by the $\mathrm{Na}-$ tional Institute on Drug Abuse) during six $1 \mathrm{hr}$ daily sessions that were separated by $5 \mathrm{~min}$ over $10 \mathrm{~d}$. Cocaine was dissolved in saline and was self-administered at a dose of $0.75 \mathrm{mg} / \mathrm{kg}$ per infusion; the volume of each infusion was $0.10 \mathrm{ml}$, and cocaine was delivered over $3.75 \mathrm{sec}$. The selfadministration sessions started at the onset of the dark cycle. Responding on the active lever resulted in cocaine infusions that were accompanied by a $5 \mathrm{sec}$ tone $(2900 \mathrm{~Hz}, 20 \mathrm{~dB}$ above background noise level) and light ( $7.5 \mathrm{~W}$ white light located $7 \mathrm{~cm}$ above the active lever) compound cue. A fixed-ratio-1 schedule (each lever press is reinforced) was used, with a 40 sec time out period after each infusion. Responses on the inactive lever were recorded, but had no programmed consequences. Each session began with the insertion of the active lever and the illumination of a red house light that remained on for the entire session. At the end of each session, the house light was turned off, and the active lever was retracted. To facilitate the acquisition of cocaine self-administration, food was removed from the chambers during the $6 \mathrm{hr}$ sessions of the first $5 \mathrm{~d}$ of the training phase. The number of cocaine infusions was limited to $20 / \mathrm{hr}$ to minimize overdose. At the end of the training phase, the groups in the different conditions of each experiment (see below) were matched for their cocaine intake during training. Thirty-seven rats were excluded because of loss of catheter patency during training $(n=16)$, poor health or death during the training or withdrawal phases $(n=16)$, or failure to acquire cocaine self-administration ( $<15$ infusions per day; $n=5)$.

\section{Withdrawal phase}

At the end of training, rats were kept in the self-administration chambers and were handled daily until the tests for cocaine seeking on day 3 . After this test, rats were returned to the animal facility and were handled three times per week until the second test on day 10 or 30 .

\section{Tests for cocaine seeking}

These tests consisted of two $1 \mathrm{hr}$ extinction sessions that were separated by $5 \mathrm{~min}$. The testing conditions were the same as in training, with the exception that responses on the previously active lever were not reinforced with cocaine. The tests started at the onset of the dark cycle. Each session began with the insertion of the active lever and the illumination of the red house light that remained on for the entire session. At the end of each session, the house light was turned off, and the active lever was retracted. Each lever press during the test sessions resulted in the contingent presentation of the tone-light cue previously paired with cocaine infusions.

Experiment 1: effect of intra-VTA infusions of BDNF or NGF on cocaine seeking. BDNF or NGF was infused 1-2 hr after the last training session, and each rat was tested for cocaine seeking on days 3 and 10 of withdrawal from cocaine. Four groups of rats $(n=7-11)$ were infused with $\operatorname{BDNF}(0$, $0.075,0.25$, or $0.75 \mu \mathrm{g})$, and three groups of rats $(n=7-8)$ were infused with NGF $(0,0.075$, or $0.75 \mu \mathrm{g})$. The doses of the growth factors and the delay period between the infusions and the test days are based on the study of Shirayama et al. (2002). These authors found that BDNF induces antidepressant-like effects 3 and $10 \mathrm{~d}$ after a single intrahippocampal infusion. NGF was used as a control growth factor because it is not colocalized with midbrain DA neurons (Seroogy et al., 1994), and it does not alter cocaine-induced locomotion (Pierce and Bari, 2001). Additionally, we found that NGF levels in the VTA are not altered after withdrawal from cocaine (Grimm et al., 2003).

Experiment 2: effect of intra-SN infusions of BDNF on cocaine seeking. To examine the anatomical specificity of the effect of BDNF on cocaine seeking, the high dose of the BDNF was infused into the nearby $\mathrm{SN}$, the dopamine cell body region of the nigrostriatal system. Two groups of rats ( $n=7$ per group) were used. BDNF $(0$ or $0.75 \mu \mathrm{g})$ was infused $1-2 \mathrm{hr}$ after the last training session, and each rat was tested for cocaine seeking on day 3 and 10 of withdrawal from cocaine.

Experiment 3: effect of U0126 on the enhancement of cocaine seeking induced by intra-VTA BDNF infusions. To examine the role of the MAPK pathway in the effect of intra-VTA infusions of BDNF on cocaine seek- ing, U0126, a MEK inhibitor, was used. MEK is a kinase that phosphorylates the extracellular signal-regulated kinase (ERK), a key step in the MAPK signaling pathway (Sweatt, 2001). Four groups of rats $(n=9-11)$ were used in a $2($ BDNF dose: 0 or $0.75 \mu \mathrm{g}) \times 2$ (U0126 dose: 0 or $1 \mu \mathrm{g})$ factorial design. Each rat was tested on days 3 and 10 of withdrawal. Rats received bilateral intra-VTA infusions of U0126 or its vehicle $(10 \%$ DMSO solution) 20 min before infusions of BDNF or its vehicle. The dose of U0126 and the pretreatment time were chosen based on previous studies demonstrating that intracranial infusions of the MEK inhibitor block the behavioral effects of BDNF and BDNF-induced ERK phosphorylation (Shirayama et al., 2002) and also block Pavlovian fear conditioning and conditioning-induced ERK phosphorylation (Schafe et al., 2000).

Experiment 4: acute effect of intra-VTA infusions of BDNF on cocaine seeking. To further characterize the effect of intra-VTA BDNF infusions on cocaine seeking, we examined whether acute infusions of BDNF, given just before the test session on day 3 of withdrawal, would enhance cocaine seeking. Two groups of rats ( $n=7$ per group) were used, and BDNF $(0$ or $0.75 \mu \mathrm{g})$ was infused $2 \mathrm{hr}$ before the $2 \mathrm{hr}$ test session. The 2 hr pretreatment time is based on the results of Shirayama et al. (2002), who found that immunolabeling of BDNF is maximal $2 \mathrm{hr}$ after intrahippocampal injection of the growth factor. These authors also found that increased levels of BDNF are detected after $24 \mathrm{hr}$, but not $72 \mathrm{hr}$, after infusions.

Experiment 5: long-term effect of intra-VTA infusions of BDNF on cocaine seeking. To further study the time course of the effect of intra-VTA BDNF infusions on cocaine seeking, we examined lever pressing after these infusions after 3 and $30 \mathrm{~d}$ of withdrawal. Two groups of rats $(n=$ $13-15$ ) were used. BDNF ( 0 or $0.75 \mu \mathrm{g}$ ) was infused $1-2 \mathrm{hr}$ after the last training session, and each rat was tested on days 3 and 30 of withdrawal from cocaine. The number of rats used was larger than those in experiments 1-4 to detect group differences on day 30 , in which cocaine seeking is much higher and more variable than during early withdrawal (Grimm et al., 2001).

\section{Statistical analyses}

The data from the test sessions were analyzed separately for total (nonreinforced) active- and inactive-lever responses. Data were analyzed with mixed-model ANOVAs, using the appropriate between- and withinsubjects factors (see Results). Post hoc analyses of significant effects were followed by a Fisher's protected least significant difference test (twotailed). Also, in some of the experiments, we found significant effects of the withdrawal period on inactive-lever responding, a potential measure of general (non-directed) activity and response generalization (Shalev et al., 2002). Thus, data were re-analyzed, using ANOVA of change-scores (active-lever minus inactive-lever presses) and ANCOVA, with the inactive-lever values as covariates. These change-score and covariate analyses replicated those of active-lever responding (results not shown), suggesting that inactive-lever responding cannot account for the results obtained for active-lever responding.

\section{Results}

Rats demonstrated reliable cocaine self-administration during the training phase of experiments $1-5$, and no significant differences were observed in cocaine intake across these experiments $(p>0.4)$. The mean \pm SEM number of cocaine infusions (data collapsed from experiments $1-5$, total $n=151$ ) on the last three training days were $65.3 \pm 2.1,68.6 \pm 2.0$, and $68.6 \pm 1.9$, respectively. The tips of the injectors for VTA microinjections were located in the middle part of the VTA (Fig. 1D).

\section{Experiment 1: effect of intra-VTA infusions of BDNF or NGF on cocaine seeking}

Figure 1 shows the mean \pm SEM number of nonreinforced presses on the active lever during the tests for cocaine seeking under extinction conditions conducted 3 and $10 \mathrm{~d}$ after withdrawal from cocaine in rats given intra-VTA infusions of vehicle, 

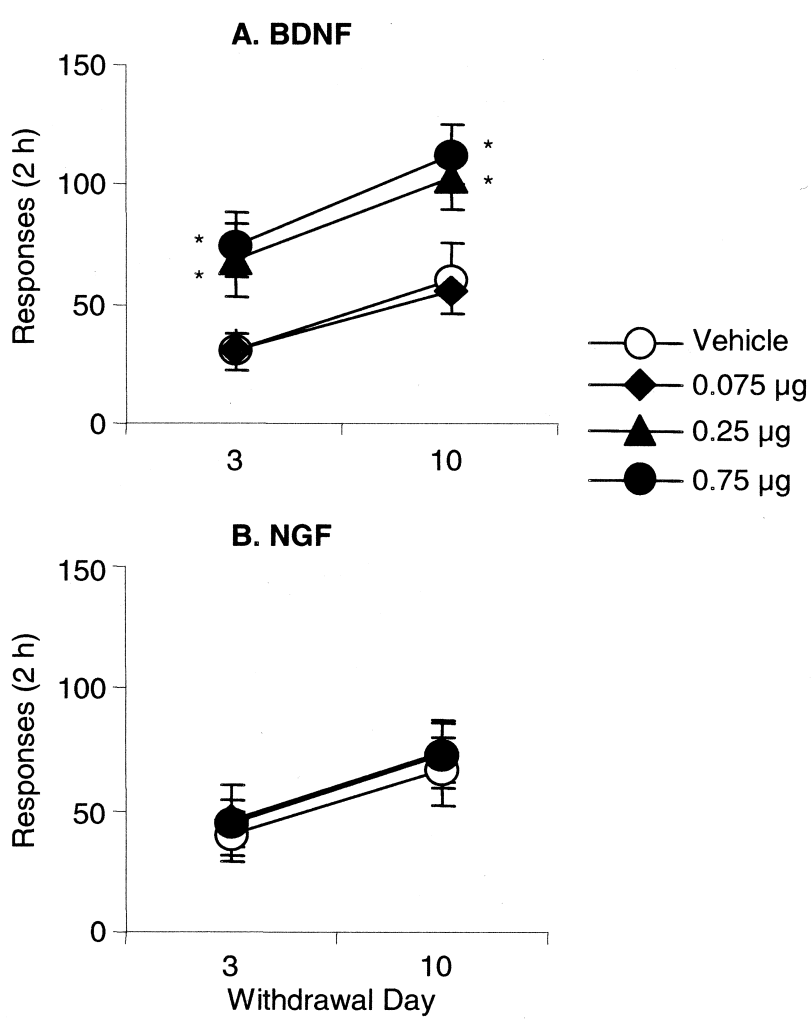

C. Timeline

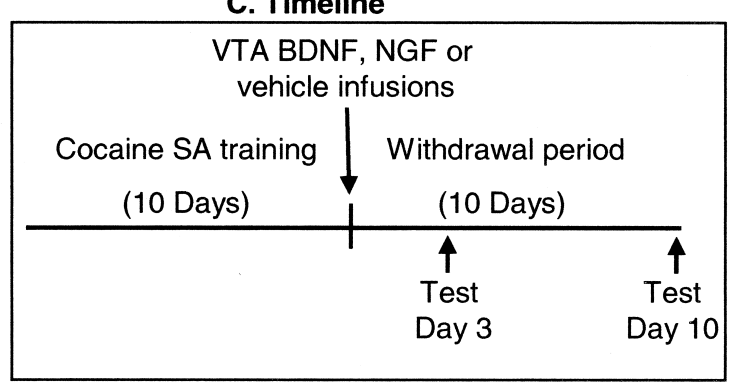

D. Cannulae placement

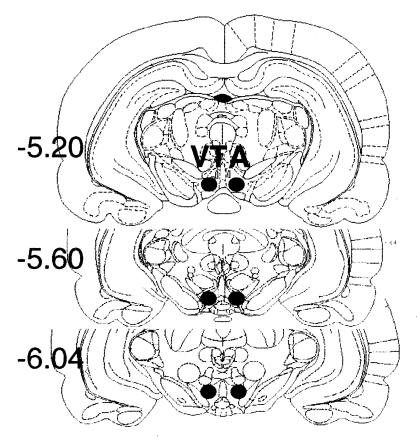

Figure 1. Ventral tegmental area infusions of $\operatorname{BDNF}(A)$, but not $\operatorname{NGF}(B)$, potentiate cocaine seeking induced by re-exposure to cocaine cues after 3 and $10 \mathrm{~d}$ of withdrawal. Data are mean ( \pm SEM) responses per $2 \mathrm{hr}$ on the previously active lever during the tests for cocaine seeking performed under extinction conditions after 3 and $10 \mathrm{~d}$ of withdrawal from cocaine. During the test sessions, cocaine was not available, and lever presses resulted in the delivery of the tonelight cue previously paired with drug infusions. Vehicle, BDNF, or NGF was infused bilaterally into the VTA 1-2 hr after the last training session. C, Timeline of the experiment. D, Schematic illustration of the approximate cannula placements within the VTA of the 56 rats used in experiment 1. Coronal sections were reproduced from the atlas of Paxinos and Watson (1998), and coordinates are posterior to bregma in millimeters. ${ }^{*}$ Significantly different from vehicle, $p<$ 0.05 ( $n=7-11$ per group). SA, Self-administration.
BDNF, or NGF, 1-2 hr after the last training session. The mixed ANOVA included the between-subjects factor of BDNF dose or NGF dose and the within-subjects factor of withdrawal day.

\section{$B D N F$}

Cocaine seeking during the extinction tests was higher after $10 \mathrm{~d}$ than after $3 \mathrm{~d}$, confirming our previous findings on the progressive increase in drug seeking induced by exposure to cocaine cues after withdrawal. More important, the two higher doses of BDNF significantly increased cocaine seeking after 3 and $10 \mathrm{~d}$ of withdrawal. Analysis of active-lever responding revealed significant effects of BDNF dose $\left(F_{(3,29)}=8.3 ; p<0.01\right)$ and withdrawal day $\left(F_{(1,29)}=17.1 ; p<0.01\right)$. Inactive-lever responding was significantly lower than active-lever responding during the extinction tests $(p<0.001)$. No significant effects of BDNF dose $(p=0.9)$ or withdrawal day ( $p=0.1$ ) were found for inactive-lever responding. Inactive responding on day 3 (group means 0.8-5.9 responses per $2 \mathrm{hr}$ ), however, tended to be lower than the responding on day 10 (group means 5.9-12.4 responses per $2 \mathrm{hr}$ ). Finally, no significant changes in weight gain were observed after the intra-VTA BDNF infusions in experiment 1 or in the other experiments (data not shown).

\section{NGF}

Cocaine seeking during the extinction tests was higher after $10 \mathrm{~d}$ than after $3 \mathrm{~d}$, but no group differences were observed after infusions of the different doses of NGF. Analysis of active-lever responding revealed a significant effect of withdrawal day $\left(F_{(1,12)}=\right.$ 9.0; $p<0.01)$. The effect of NGF dose was not significant $(p=$ $1.0)$. Inactive-lever responding was significantly lower than active-lever responding during the tests for cocaine seeking $(p<$ $0.001)$. The effect of NGF dose on inactive-lever responding was not significant $(p=0.4$ ), but a significant effect was found for withdrawal day $\left(F_{(1,12)}=6.9 ; p<0.05\right)$. Inactive responding on day 3 (group means $2.9-7.5$ responses per $2 \mathrm{hr}$ ) was lower than the responding on day 10 (group means 8.1-15.6 responses per 2 hr).

\section{Experiment 2: effect of intra-SN infusions of BDNF on cocaine seeking}

Figure 2 shows the mean number of nonreinforced presses on the active-lever during the tests for cocaine seeking in rats given intra-SN infusions of vehicle or BDNF 1-2 hr after the last training session. The mixed ANOVA included the between-subjects factor of BDNF dose and the within-subjects factor of withdrawal day. Cocaine seeking during the test sessions was higher after $10 \mathrm{~d}$ than after $3 \mathrm{~d}$, but no group differences were observed after infusions of the high dose of BDNF into the SN. Analysis of activelever responding revealed a significant effect of withdrawal day $\left(F_{(1,12)}=13.7 ; p<0.01\right)$, but not of BDNF dose $(p=0.93)$. Inactive-lever responding was significantly lower than activelever responding during the test sessions $(p<0.001)$. No significant effects of BDNF dose $(p=0.35)$ or withdrawal day $(p=$ 0.52 ) were found for inactive-lever responding: day 3 (group means $4.1-6.1$ responses per $2 \mathrm{hr}$ ) was similar to that of day 10 (group means 5.1-7.7 responses per $2 \mathrm{hr}$ ).

Experiment 3: effect of U0126 on the enhancement of cocaine seeking induced by intra-VTA BDNF infusions

Figure 3 shows the mean number of nonreinforced presses on the active-lever during the tests for cocaine seeking in rats given intra-VTA infusions of U0126, BDNF, or their respective vehicles 1-2 hr after the last training session. The mixed ANOVA included 


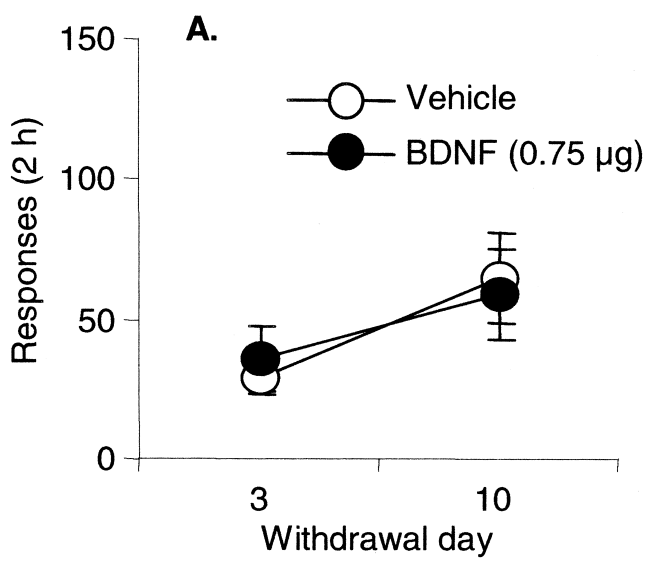

B.

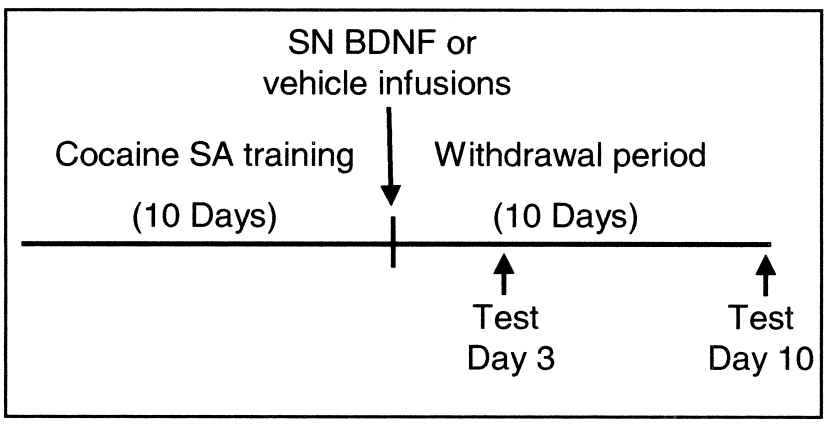

C.

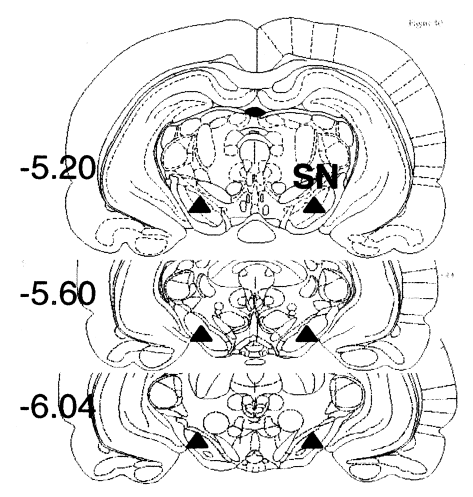

Figure 2. Substantia nigra infusions of BDNF have no effect on cocaine seeking induced by re-exposure to cocaine cues after 3 and $10 \mathrm{~d}$ of withdrawal. $A$, Mean ( \pm SEM) responses per $2 \mathrm{hr}$ on the previously active lever during the tests for cocaine seeking conducted after 3 and $10 \mathrm{~d}$ of withdrawal from cocaine. During the test sessions, cocaine was not available, and lever presses resulted in the delivery of the tone-light cue previously paired with drug infusions. Vehicle or BDNF was infused bilaterally into the $\mathrm{SN} 1-2 \mathrm{hr}$ after the last training session ( $n=7$ per group). $B$, Timeline of the experiment. C, Schematic illustration of the approximate cannula placements within the $S \mathrm{~N}$ of the 14 rats used in experiment 2. Coronal sections were reproduced from the atlas of Paxinos and Watson (1998), and coordinates are posterior to bregma in millimeters. SA, Self-administration.

the between-subjects factor of U0126 dose and BDNF dose and the within-subjects factor of withdrawal day. As in experiment 1, responding during the tests for cocaine seeking was higher after $10 \mathrm{~d}$ than after $3 \mathrm{~d}$, and BDNF infusions enhanced responding on both test days. More important, this effect of BDNF was blocked by infusion of U0126 at a dose that had no effect on cocaine seeking when infused without BDNF. Analysis of active-lever re-

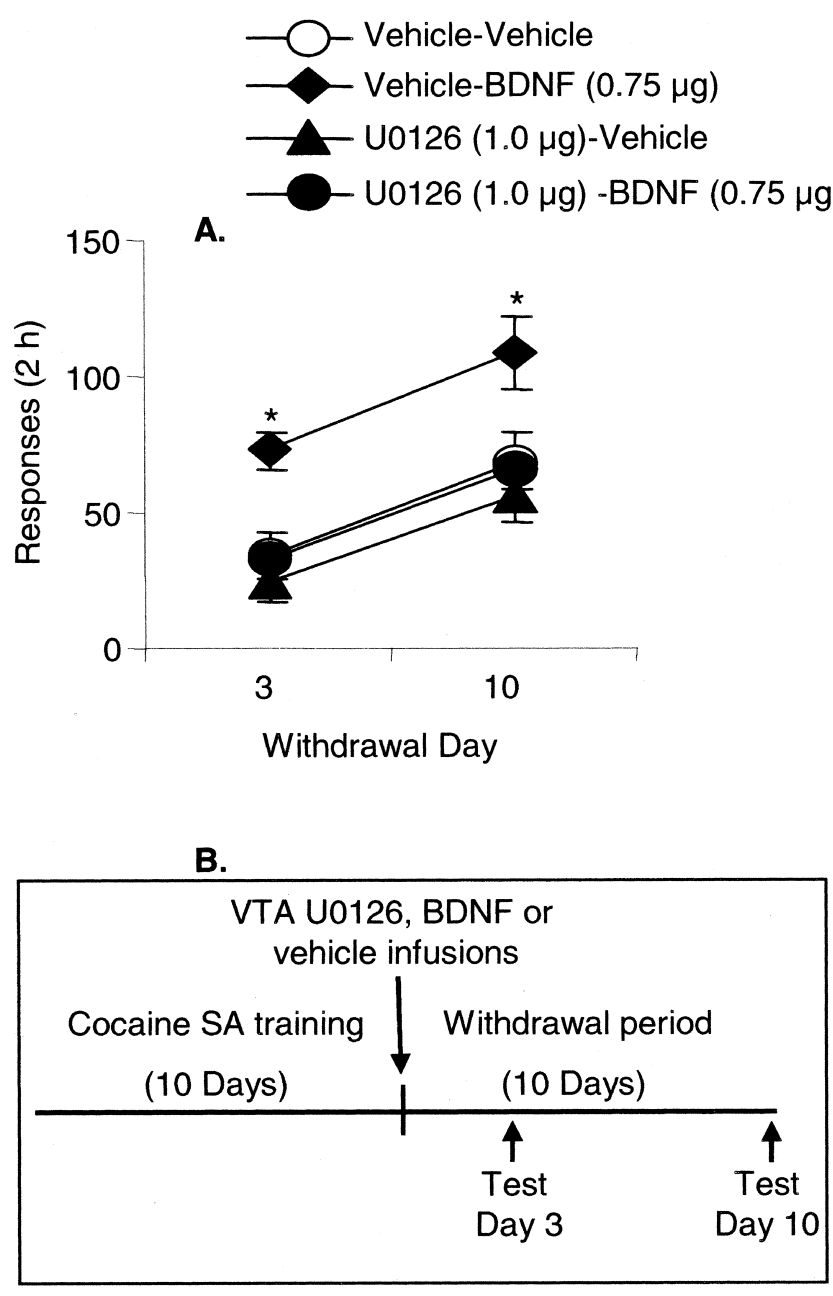

Figure 3. Ventral tegmental area infusions of the MEK inhibitor U0126 attenuate BDNFinduced potentiation of cocaine seeking induced by re-exposure to cocaine cues after 3 and $10 \mathrm{~d}$ of withdrawal. $A$, Mean ( \pm SEM) responses per $2 \mathrm{hr}$ on the previously active lever during the tests for cocaine seeking conducted after 3 and $10 \mathrm{~d}$ of withdrawal from cocaine. During the test sessions, cocaine was not available, and lever presses resulted in the delivery of the tone-light cue previously paired with drug infusions. Infusions of U0126 or its vehicle (10\% DMSO) were given $20 \mathrm{~min}$ before the infusions of BDNF or its vehicle, which were given $1-2 \mathrm{hr}$ after the last training session. $B$, Timeline of the experiment. *Significantly different from the other groups, $p<0.05$ ( $n=9-11$ per group). SA, Self-administration.

sponding revealed significant effects of withdrawal day $\left(F_{(1,35)}=\right.$ 59.6; $p<0.01)$ and U0126 dose by BDNF dose $\left(F_{(1,35)}=4.3 ; p<\right.$ $0.05)$. Inactive-lever responding was significantly lower than active-lever responding during the test sessions $(p<0.001)$. Analysis of inactive-lever responding revealed a main effect of withdrawal day $\left(F_{(1,35)}=23.1 ; p<0.01\right)$, but the effects of U0126 dose, BDNF dose, or U0126 dose by BDNF dose were not significant ( $p$ values $>0.45$ ). The effect of withdrawal day is attributable to the lower responding on day 3 (group means 1.3-3.1 responses per $2 \mathrm{hr}$ ) than on day 10 (group means 7.2-10.2 responses per $2 \mathrm{hr}$ ).

Experiment 4: acute effect of intra-VTA infusions of BDNF on cocaine seeking

Figure 4 shows the mean number of nonreinforced presses on the active-lever during the tests for cocaine seeking in rats given intra-VTA infusions of vehicle or the high dose of BDNF $(0.75$ $\mu \mathrm{g}) 2 \mathrm{hr}$ before the test session on day 3 of withdrawal. The ANOVA included the between-subjects factor of BDNF dose. 


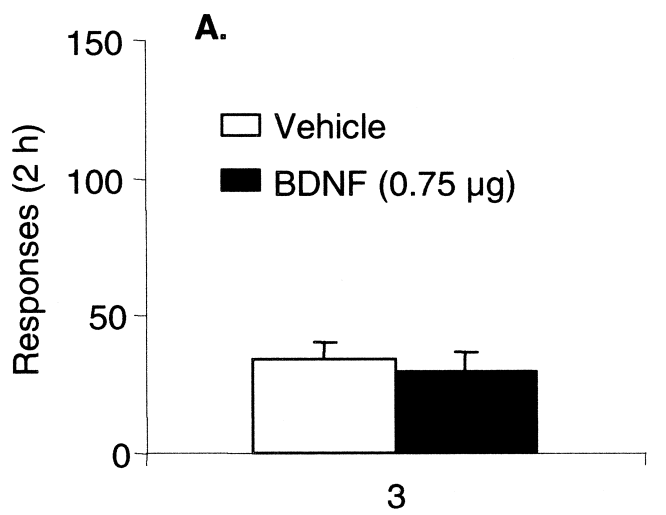

Withdrawal day

B.

\begin{tabular}{|cc|}
\hline $\begin{array}{c}\text { VTA BDNF or } \\
\text { vehicle infusions } \\
\text { Cocaine SA training } \\
\text { (10 days) }\end{array}$ & $\begin{array}{c}\text { Withdrawal period } \\
\text { (3 days) }\end{array}$ \\
\hline & \\
& \\
& Test \\
& Day 3 \\
& \\
& \\
&
\end{tabular}

Figure 4. Ventral tegmental area infusions of BDNF $2 \mathrm{hr}$ before testing on day 3 of withdrawal have no effect on cocaine seeking induced by re-exposure to cocaine cues. $A$, Mean ( \pm SEM) responses per $2 \mathrm{hr}$ on the previously active lever during the test session conducted after $3 \mathrm{~d}$ of withdrawal from cocaine. During testing, cocaine was not available, and lever presses resulted in the delivery of the tone-light cue previously paired with drug infusions. Vehicle or BDNF was infused bilaterally into the VTA $2 \mathrm{hr}$ before the test session. $B$, Timeline of the experiment ( $n=7$ per group). SA, Self-administration.

Infusions of BDNF $2 \mathrm{hr}$ before the test for cocaine seeking had no effect on active or inactive-lever responding ( $p$ values $>0.2$ ). Inactive-lever responding was significantly lower $(p<0.001)$ than active-lever responding during the tests.

\section{Experiment 5: long-term effect of intra-VTA infusion of BDNF on cocaine seeking}

Figure 5 shows the mean number of nonreinforced presses on the active lever during the tests for cocaine seeking conducted 3 and $30 \mathrm{~d}$ after withdrawal from cocaine in rats given intra-VTA infusions of vehicle or BDNF 1-2 hr after the last training session. The mixed ANOVA included the between-subjects factor of BDNF dose and the within-subjects factor of withdrawal day. Cocaine seeking during testing was higher after $30 \mathrm{~d}$ than after $3 \mathrm{~d}$. More important, the higher dose of BDNF significantly increased responding after both 3 and $30 \mathrm{~d}$ of withdrawal. Analysis of activelever responding revealed significant effects of BDNF dose $\left(F_{(1,26)}\right.$ $=21.6 ; p<0.01)$ and withdrawal day $\left(F_{(1,26)}=34.1 ; p<0.01\right)$. Inactive-lever responding was significantly lower than activelever responding during the tests for cocaine seeking $(p<0.001)$. Analysis of inactive-lever responding revealed an effect of withdrawal day $\left(F_{(1,35)}=23.1 ; p<0.01\right)$, but not of BDNF dose $(p=$ $0.7)$. The effect of withdrawal day is caused by the lower responding on day 3 than the responding on day 30.

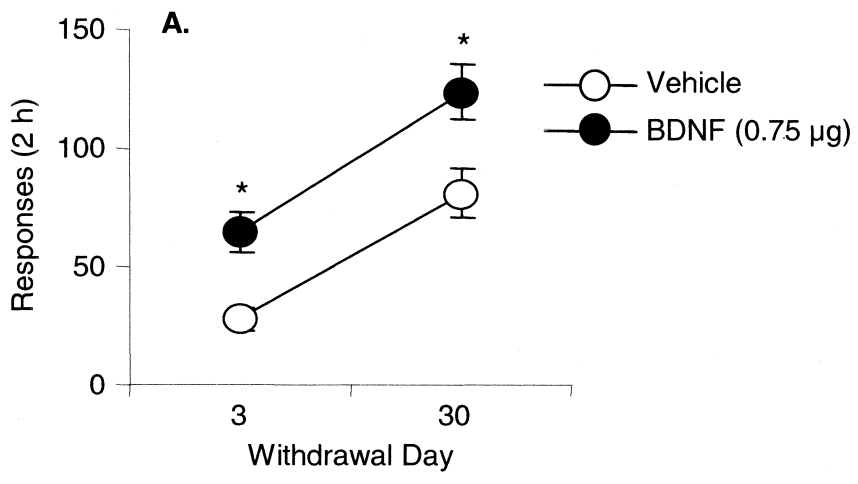

B.

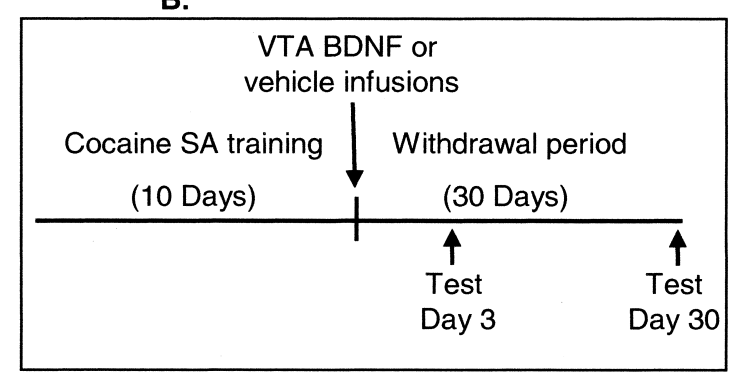

Figure 5. Ventral tegmental area infusions of BDNF potentiate cocaine seeking induced by re-exposure to cocaine cues after 3 and $30 \mathrm{~d}$ of withdrawal. A, Mean ( \pm SEM) responses per $2 \mathrm{hr}$ on the previously active lever during the tests for cocaine seeking conducted after 3 and $30 \mathrm{~d}$ of withdrawal from cocaine. During the test sessions, cocaine was not available, and lever presses resulted in the delivery of the tone-light cue previously paired with drug infusions. Vehicle or BDNF was infused bilaterally into the VTA $1-2 \mathrm{hr}$ after the last training session. $B$, Timeline of the experiment. *Significantly different from vehicle, $p<0.05$ ( $n=13-15$ per group). SA, Self-administration.

\section{Discussion}

Using a rat relapse model, we previously found that cocaine seeking induced by re-exposure to cocaine-associated cues progressively increases over the first months of withdrawal (Grimm et al., 2001), an effect associated with increases in BDNF levels in mesolimbic areas (Grimm et al., 2003). Based on these data and those demonstrating long-lasting behavioral effects of intracranial BDNF infusions (Shirayama et al., 2002), we hypothesized that intra-VTA BDNF infusions, given at the end of the training phase, would enhance cocaine seeking during the first days of withdrawal; during early withdrawal, cocaine seeking and BDNF levels in the VTA are lower than after 1-3 months of withdrawal (Grimm et al., 2001, 2003).

We found that intra-VTA BDNF infusions enhance cocaine seeking for up to $30 \mathrm{~d}$ after withdrawal from cocaine. This effect is blocked by a MEK inhibitor, suggesting that BDNF-induced potentiation of cocaine seeking is mediated by the MAPK pathway. Importantly, the effects of intra-VTA infusions of BDNF on cocaine seeking are temporally, anatomically, growth factor, and behaviorally specific. First, intra-VTA infusions of BDNF $2 \mathrm{hr}$ before the tests for cocaine seeking were not effective. Second, infusions of BDNF into the nearby SN or intra-VTA infusions of NGF had no effect on cocaine seeking. Finally, intra-VTA BDNF infusions had no effect on responding on the inactive lever, which was not associated with cocaine infusions during training.

\section{Methodological considerations}

Several methodological issues should be considered in the interpretation of the present data. First, in studies using intracranial 
drug infusions, drugs may diffuse away from the injection site and act in adjacent areas (Wise and Hoffman, 1992). However, it is unlikely that the effects of intra-VTA BDNF are caused by its diffusion to nearby sites because infusions of BDNF into the SN had no effect on cocaine seeking. Furthermore, after intracranial infusions, BDNF remains localized within $\sim 0.5 \mathrm{~mm}$ of the injection site (Shirayama et al., 2002). On the other hand, it cannot be ruled out that the behavioral effects observed here are attributable to anterograde transport of BDNF (Altar and DiStefano, 1998) from the VTA to mesolimbic projection areas such as the accumbens and amygdala.

Second, increased lever pressing during testing may be caused by BDNF-induced locomotion. Infusions of BDNF into midbrain dopamine areas increase spontaneous (Martin-Iverson and Altar, 1996) and cocaine-induced (Horger et al., 1999; Pierce et al., 1999) locomotion. However, it is unlikely that BDNFinduced locomotion can account for our data. Intra-VTA BDNF infusions had no effect on inactive-lever responding (a potential measure of general activity and/or response generalization) (Shalev et al., 2002), and infusions of BDNF $2 \mathrm{hr}$ before testing, at doses previously shown to increase locomotion (Pierce et al., 1999), had no effect on cocaine seeking.

Third, an unexpected finding was that responding on the inactive lever during the extinction tests was higher after 10 or $30 \mathrm{~d}$ of withdrawal than after $3 \mathrm{~d}$ in two of the four experiments. These data are different from those of our recent studies in which we found that time-dependent increases in inactive-lever responding only emerge after 6 months of withdrawal (Shaham, 2002), an observation that may be related to time-dependent flattening of the generalization gradient of conditioned cues after reward removal (Riccio et al., 1992). In our previous studies, different groups of rats were tested at the different withdrawal periods, whereas, here, rats were tested repeatedly after 3 and 10 or $30 \mathrm{~d}$. Thus, repeated testing may have accelerated response generalization, resulting in higher inactive-lever responding on the second test for cocaine seeking that was conducted after 10 or $30 \mathrm{~d}$.

\section{BDNF and cocaine seeking after withdrawal: a behavioral perspective}

The exact role of BDNF in the VTA in the incubation of cocaine seeking after withdrawal is not known. Incubation of reward seeking also occurs over the first weeks after withdrawal from oral sucrose self-administration. This incubation, however, is not associated with increases in mesolimbic BDNF levels and it dissipates after 2-3 months, a time period in which responsiveness to cocaine cues is maximal and is accompanied by increases in mesolimbic BDNF levels (Shaham, 2002; Grimm et al., 2003). These observations suggest that although mesolimbic BDNF may be involved in the persistent responsiveness to cocaine cues after prolonged withdrawal periods (Grimm et al., 2003), it is probably not directly involved in the basic process underlying the incubation of responsiveness to drug and nondrug reward cues.

The present data appear to support this postulation. IntraVTA BDNF infusions induced a parallel upward shift in the withdrawal period-extinction-response curve, without having an effect on the slope of this time-response function (Figs. 1-3, 5). Furthermore, intra-VTA infusions of the MEK inhibitor U0126, which blocks BDNF-induced potentiation of cocaine seeking, had no effect on the slope of the time-response curve (Fig. 3). Thus, the actions of BDNF in the VTA do not appear to mediate the basic process of incubation of reward seeking, which controls the slope of the time-response curve. Rather, BDNF enhances cocaine seeking after intra-VTA injections and possibly main- tains heightened cocaine seeking at the late withdrawal periods, when its expression is increased in mesolimbic areas after 1 and 3 months (Grimm et al., 2003).

\section{BDNF and cocaine seeking after withdrawal: a molecular perspective}

We found that a single intra-VTA BDNF infusion has longlasting effects on cocaine seeking for up to $30 \mathrm{~d}$ after withdrawal. These effects are blocked by the MEK inhibitor U0126, suggesting the involvement of the MAPK pathway in BDNF actions. These data are in agreement with those of Shirayama et al. (2002), who found that the effects of intrahippocampal BDNF infusions on learned helplessness behavior 3 or $10 \mathrm{~d}$ after these infusions are mediated by the MAPK pathway. In this study, BDNF infusions also induced ERK phosphorylation and Fos expression (a MAPK pathway-mediated effect), further confirming the involvement of the MAPK pathway in the behavioral effects of BDNF.

The neuronal processes downstream from the MAPK pathway that are involved in the long-lasting effects of intra-VTA BDNF on cocaine seeking are not known. After acute administration, BDNF enhances excitatory synaptic transmission (Poo, 2001) and increases dopamine cell firing in midbrain cell body neurons (Shen et al., 1994). These potentially acute effects of BDNF, however, had no effect on cocaine seeking when the growth factor was infused into the VTA $2 \mathrm{hr}$ before testing. BDNF also has long-term effects on other forms of synaptic plasticity, such as alterations in neuronal morphology and synaptic remodeling (McFarlane, 2000; Poo, 2001). Thus, BDNF infusions may have produced morphological and other synaptic alterations in the VTA, and possibly also produced neuronal changes in mesolimbic projection areas via anterograde transport of BDNF (Altar and DiStefano, 1998) that may underlie the enhanced cuecontrolled cocaine seeking after withdrawal.

Intra-VTA BDNF infusions may enhance the behavioral effects of cocaine or cocaine-associated cues by reversing certain cocaine-induced neuroadaptations in the VTA and accumbens, including increases in tyrosine hydroxylase (VTA) and PKA activity (accumbens) (Berhow et al., 1995). Because BDNF was found to potentiate certain behavioral effects of cocaine, these adaptations in tyrosine hydroxylase and PKA activity were hypothesized to be involved in tolerance to the behavioral effects of cocaine (Horger et al., 1999). Tentative support for this hypothesis is provided by our findings that the time course of the alterations in tyrosine hydroxylase in the VTA and PKA activity in the accumbens (Lu et al., 2003) is opposite from that of BDNF expression (Grimm et al., 2003) in these brain areas after withdrawal from cocaine.

Finally, the main hypothesis that guides current neurobiological research on cocaine relapse is that chronic drug exposure causes long-lasting neuroadaptations in the brain that underlie relapse vulnerability during abstinence periods (Nestler, 2001; Everitt and Wolf, 2002; Bonci et al., 2003; Kalivas and McFarland, 2003). However, despite numerous reports on cocaine-induced neuroadaptations (Nestler, 2001; Kalivas et al., 2003), a causal relationship between specific neuroadaptations and drug relapse has not been clearly established [Shaham et al., 2003; but see Baker et al. (2003) for a recent exception]. We previously found that the time-dependent changes in BDNF levels in mesolimbic areas are associated with increased cocaine seeking after withdrawal (Grimm et al., 2003). Here, we found that a single intraVTA infusion of BDNF, a growth factor involved in synaptic plasticity, has long-lasting effects on cocaine seeking induced by re-exposure to cocaine-associated cues after withdrawal. These 
data suggest that BDNF-mediated neuroadaptations in mesolimbic areas may be involved in the persistent cocaine seeking in rats after prolonged withdrawal periods and possibly play a role in drug seeking in humans after prolonged abstinence periods.

\section{References}

Altar CA, DiStefano PS (1998) Neurotrophin trafficking by anterograde transport. Trends Neurosci 21:433-437.

Baker DA, McFarland K, Lake RW, Shen H, Tang XC, Toda S, Kalivas PW (2003) Neuroadaptations in cystine-glutamate exchange underlie cocaine relapse. Nat Neurosci 6:743-749.

Balleine BW, Dickinson A (1998) Goal-directed instrumental action: contingency and incentive learning and their cortical substrates. Neuropharmacology 37:407-419.

Berhow MT, Russell DS, Terwilliger RZ, Beitner-Johnson D, Self DW, Lindsay RM, Nestler EJ (1995) Influence of neurotrophic factors on morphine- and cocaine-induced biochemical changes in the mesolimbic dopamine system. Neuroscience 68:969-979.

Bonci A, Bernardi G, Grillner P, Mercuri NB (2003) The dopaminecontaining neuron: maestro or simple musician in the orchestra of addiction? Trends Pharmacol Sci 24:172-177.

Ciccocioppo R, Sanna PP, Weiss F (2001) Cocaine-predictive stimulus induces drug-seeking behavior and neural activation in limbic brain regions after multiple months of abstinence: reversal by $\mathrm{D}(1)$ antagonists. Proc Natl Acad Sci USA 98:1976-1981.

Everitt BJ, Wolf ME (2002) Psychomotor stimulant addiction: a neural systems perspective. J Neurosci 22:3312-3320.

Grimm JW, Hope BT, Wise RA, Shaham Y (2001) Incubation of cocaine craving after withdrawal. Nature 412:141-142.

Grimm JW, Shaham Y, Hope BT (2002) Effect of the cocaine and sucrose withdrawal period on extinction behavior, cue-induced reinstatement and protein levels of the dopamine transporter and tyrosine hydroxylase in limbic and cortical areas in rats. Behav Pharmacol 13:379-388.

Grimm JW, Lu L, Hayashi T, Hope BT, Su TP, Shaham Y (2003) Timedependent increases in brain-derived neurotrophic factor protein levels within the mesolimbic dopamine system after withdrawal from cocaine: implications for incubation of cocaine craving. J Neurosci 23:742-747.

Horger BA, Iyasere CA, Berhow MT, Messer CJ, Nestler EJ, Taylor JR (1999) Enhancement of locomotor activity and conditioned reward to cocaine by brain-derived neurotrophic factor. J Neurosci 19:4110-4122.

Hyman C, Hofer M, Barde YA, Juhasz M, Yancopoulos GD, Squinto SP, Lindsay RM (1991) BDNF is a neurotrophic factor for dopaminergic neurons of the substantia nigra. Nature 350:230-232.

Kalivas PW, McFarland K (2003) Brain circuitry and the reinstatement of cocaine seeking behavior. Psychopharmacology 168:44-56.

Kalivas PW, Toda S, Bowers MS, Baker DA, Ghasemzadeh MB (2003) The temporal sequence of changes in gene expression by drugs of abuse. Methods Mol Med 79:3-11.

Lu L, Grimm JW, Shaham Y, Hope BT (2003) Molecular neuroadaptations in the accumbens and ventral tegmental area during the first 90 days of forced abstinence from cocaine self-administration in rats. J Neurochem 85:1604-1613.

Martin-Iverson MT, Altar CA (1996) Spontaneous behaviours of rats are differentially affected by substantia nigra infusions of brain-derived neurotrophic factor and neurotrophin-3. Eur J Neurosci 8:1696-1706.

McFarlane S (2000) Dendritic morphogenesis: building an arbor. Mol Neurobiol 22:1-9.

Meredith GE, Callen S, Scheuer DA (2002) Brain-derived neurotrophic factor expression is increased in the rat amygdala, piriform cortex and hypothalamus following repeated amphetamine administration. Brain Res 949:218-227.
Nestler EJ (2001) Molecular basis of long-term plasticity underlying addiction. Nat Rev Neurosci 2:119-128.

O’Brien CP (1997) A range of research-based pharmacotherapies for addiction. Science 278:66-70.

Paxinos G, Watson C (1998) The rat brain in stereotaxic coordinates, Ed 4. San Diego: Academic.

Phillips GD, Howes SR, Whitelaw RB, Wilkinson LS, Robbins TW, Everitt BJ (1994) Isolation rearing enhances the locomotor response to cocaine and a novel environment, but impairs the intravenous self-administration of cocaine. Psychopharmacology 115:407-418.

Pierce RC, Bari AA (2001) The role of neurotrophic factors in psychostimulant-induced behavioral and neuronal plasticity. Rev Neurosci 12:95-110.

Pierce RC, Pierce-Bancroft AF, Prasad BM (1999) Neurotrophin-3 contributes to the initiation of behavioral sensitization to cocaine by activating the Ras/Mitogen-activated protein kinase signal transduction cascade. J Neurosci 19:8685-8995.

Poo MM (2001) Neurotrophins as synaptic modulators. Nat Rev Neurosci 2:24-32.

Riccio DC, Ackil J, Burch-Vernon A (1992) Forgetting of stimulus attributes: methodological implications for assessing associative phenomena. Psychol Bull 112:433-445.

Schafe GE, Atkins CM, Swank MW, Bauer EP, Sweatt JD, LeDoux JE (2000) Activation of ERK/MAP kinase in the amygdala is required for memory consolidation of Pavlovian fear conditioning. J Neurosci 20:8177-8187.

Seroogy KB, Lundgren KH, Tran TM, Guthrie KM, Isackson PJ, Gall CM (1994) Dopaminergic neurons in rat ventral midbrain express brainderived neurotrophic factor and neurotrophin-3 mRNAs. J Comp Neurol 342:321-334.

Shaham Y (2002) The drug withdrawal period and susceptibility to relapse to heroin and cocaine seeking. Behav Pharmacol 13:503.

Shaham Y, Shalev U, Lu L, De Wit H, Stewart J (2003) The reinstatement model of drug relapse: history, methodology and major findings. Psychopharmacology 168:3-20.

Shalev U, Morales M, Hope B, Yap J, Shaham Y (2001) Time-dependent changes in extinction behavior and stress-induced reinstatement of drug seeking following withdrawal from heroin in rats. Psychopharmacology 156:98-107.

Shalev U, Grimm JW, Shaham Y (2002) Neurobiology of relapse to heroin and cocaine seeking: a review. Pharmacol Rev 54:1-42.

Shen RY, Altar CA, Chiodo LA (1994) Brain-derived neurotrophic factor increases the electrical activity of pars compacta dopamine neurons in vivo. Proc Natl Acad Sci USA 91:8920-8924.

Shirayama Y, Chen AC, Nakagawa S, Russell DS, Duman RS (2002) Brainderived neurotrophic factor produces antidepressant effects in behavioral models of depression. J Neurosci 22:3251-3261.

Swanson LW (1982) The projections of the ventral tegmental area and adjacent regions: a combined fluorescent retrograde tracer and immunofluorescence study in the rat. Brain Res Bull 9:321-353.

Sweatt JD (2001) The neuronal MAP kinase cascade: a biochemical signal integration system subserving synaptic plasticity and memory. J Neurochem 76:1-10.

Thoenen H (1995) Neurotrophins and neuronal plasticity. Science 270:593-598.

Tran-Nguyen TL, Fuchs RA, Coffey GP, O’Dell LE, Baker DA, Neisewander JL (1998) Time-dependent changes in cocaine seeking behavior and dopamine overflow in the amygdala during cocaine withdrawal. Neuropsychopharmacology 19:48-59.

White FJ, Kalivas PW (1998) Neuroadaptations involved in amphetamine and cocaine addiction. Drug Alcohol Depend 51:141-153.

Wise RA, Hoffman DC (1992) Localization of drug reward mechanisms by intracranial injections. Synapse 10:247-263. 